\title{
Dimensões a considerar na pesquisa com dispositivos móveis ${ }^{1}$
}

\author{
MARCELO ALMEIDA BAIRRAL I
}

\section{Introdução}

A HISTÓRIA da humanidade é continuamente impregnada e remodelada pela criação, utilização, apropriação e reconfiguração de tecnologias. Continuamente criamos tecnologias, e elas, sinergicamente, nos redimenmensionam. Desde o seu nascimento, o pequeno humano pensante se constitui através de línguas, de máquinas, de sistemas de representação que estruturam sua experiência (Lévy, 1993, p.161).

O surgimento da internet e o avanço acentuado de suas possibilidades promoveram uma expansão sem precedentes das fronteiras da cognição e da comunicação humana. No encontro entre matemática, física, biologia, psicologias, filosofia, antropologia, sociologia, educação, comunicação e artes, as neurociências passam a fascinar pessoas pela possibilidade de compreensão dos mecanismos das emoções, pensamentos e ações, doenças e loucuras, aprendizado e esquecimento, sonhos e imaginação, fenômenos que nos definem e constituem (Ribeiro, 2013). Esses, dentre outros, são objetos de preocupação ou reconfiguração ao longo de nossa história.

Nossa mente, nosso corpo e o ambiente físico trabalham em constante sinergia (Moore-Russo; Viglietti, 2014). Nos espaços físicos pelos quais circulamos, lidamos ${ }^{2}$ com recursos tecnológicos, cognitivos, culturais etc. Alguns desses dispositivos ${ }^{3}$ são o smartphone ou o tablet, que trazem, além da mobilidade (característica de outros artefatos, o telefone sem fio, por exemplo), a convergência (várias possibilidades midiáticas em um só recurso) e a ubiquidade (a possibilidade de navegar por vários espaços graças à conectividade). Podemos também pensar na mobilidade virtual (Lemos, 2009) e até mesmo colocar nossa existência associada ao movimento, ao deslocamento e não à lógica cartesiana, na qual nossa existência está associada à premissa do pensamento.

Os Dispositivos Móveis com Toques em Tela (DMcTT), ao se constituírem numa extensão do nosso corpo, nos atravessam, e nós também os atravessamos. Com eles construímos (in)conscientemente nossas formas de ser, de estar, de nos mover, não necessariamente em nossa dimensão corporal física. Passamos a constituir corpos com tecnologias e tecnologias com corpos (Ihde, 2002). 
Neste artigo ${ }^{4}$ ilustro seis dimensões ${ }^{5}$ (contemporaneidade, sociotécnica, neurocognitiva, perceptivo-afetiva, discursivo-comunicativa, político-pedagógica) que podem ser consideradas quando DMcTT entram em cena em processos de ensino, de aprendizagem ou de pesquisa na educação científica, tecnológica e matemática. As dimensões não são campos estanques ou excludentes. As reflexões aqui tecidas constituem traços com compassos de um educador matemático. ${ }^{6}$

\section{Dimensão da contemporaneidade: dispositivo, mobilidade e territorialidade}

Atualmente, quando se fala em tecnologia móvel, é comum pensarmos apenas em celular ou tablet. Lembre-se de que temos o copo, a caneta e recursos didáticos como o compasso, a tábua de logaritmos e o transferidor, por exemplo. São tecnologias móveis e, guardadas as suas especificidades, começarei a refletir sobre a singularidade da mobilidade, articulada às ideias de fronteira $\mathrm{e}$ de território. ${ }^{7}$

Somos sujeitos contemporâneos (Agamben, 2009). A mobilidade não é uma característica apenas do nosso tempo. Além do mais, ela não existe sem a imobilidade. Uma pressupõe a outra (Lemos, 2009). Portanto, a mobilidade é contemporânea, pois ela constitui uma preocupação humana recorrente, uma reflexão sobre um tempo em que, muitas vezes, o presente não pode ser o hegemônico. Então, contemporâneo não é necessariamente o atual, o novo. Pensar no contemporâneo é pensar no sujeito que transita em diferentes tempos, sem necessariamente colocar o presente como determinante de suas ações. Um sujeito contemporâneo é o que mantém fixo o olhar no seu tempo para nele perceber não as luzes, mas o escuro (Agamben, 2009).

A ideia de dispositivo também não é recente. Aparentemente ela passa a ser usada como nova. Agamben (2009), a partir das relações de poder de Foucault, considera dispositivo como qualquer conjunto heterogêneo (linguístico ou não linguístico) que entra em nossa vida e transforma as relações e os discursos dos seres viventes. O tempo (não necessariamente físico, do relógio) e a política são exemplos de dispositivos. Também há dispositivo oriundo de um discurso militar. Um dispositivo de natureza tecnológica, por exemplo, analisa como estão dispostas as partes de um mecanismo em uma máquina ou o próprio mecanismo em si. Então, a reflexão sobre o que é um dispositivo, de como ele entra e interfere nossa vida e em nosso modo de pensar seria refletir sobre obscuridades em nossa trajetória.

A novidade de um dispositivo móvel traz luz, mas também gera sombras. Esses sombreamentos projetam-nos em tempos e espaços diferentes, singulares, complexos. Por conseguinte, articulada à característica mobilidade, trarei a noção de fronteira(s), de território(s). Ambas são preocupações que perpassam nossa história (Augé, 2010). A ideia de fronteira não é recente. Podemos agora orientar-nos a pensar o que é a mobilidade no nosso tempo, sem esquecer o passado e podendo projetar um olhar para o futuro. 
Embora o compasso e o transferidor tenham feito parte da vida estudantil de alguns de nós, atualmente temos outras formas de realizar construções e medições de ângulos ou de outros objetos matemáticos. Uma delas é o Ambiente de Geometria Dinâmica (AGD) denominado GeoGebra.
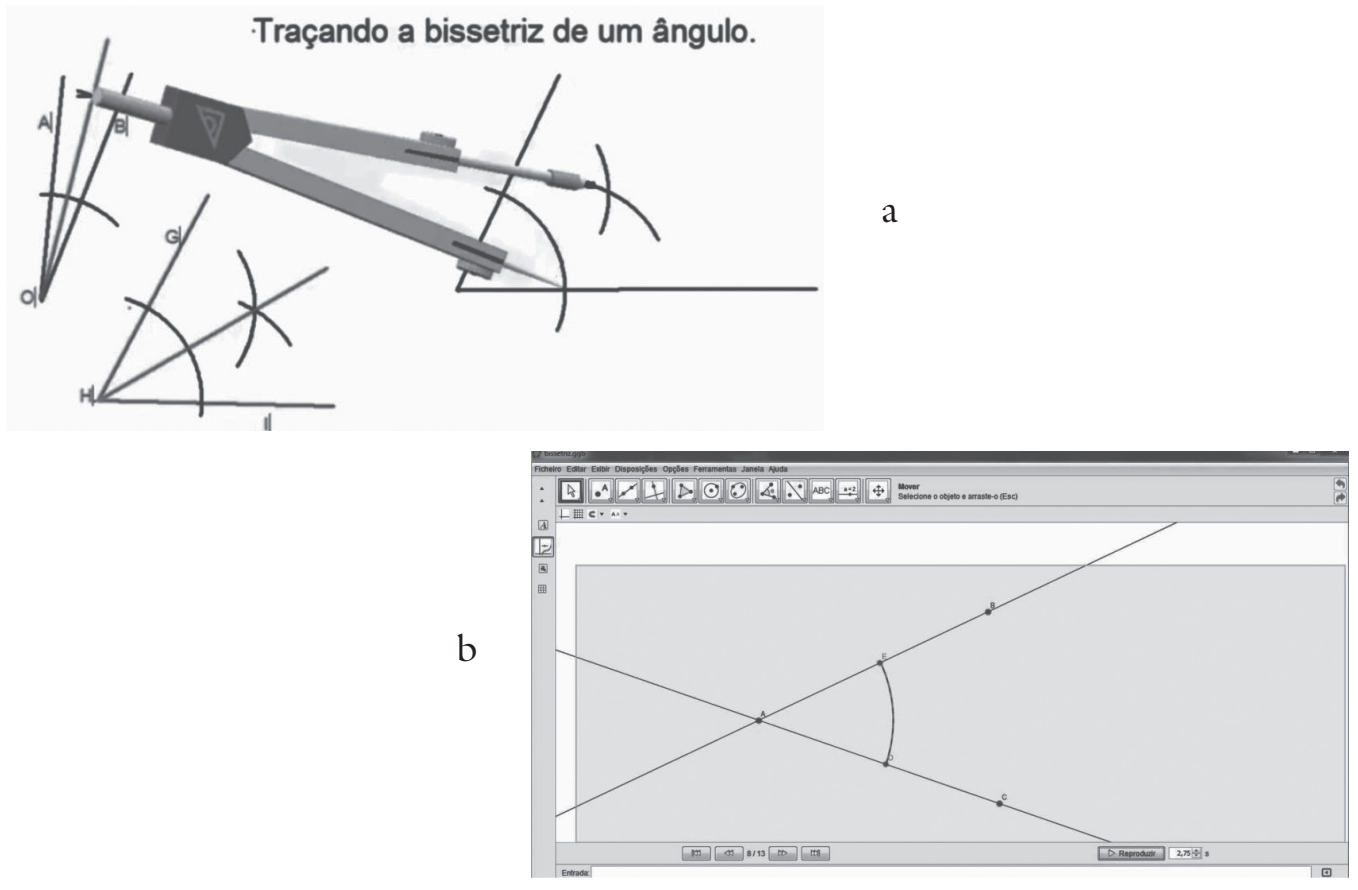

Fonte: Google pictures. ${ }^{8}$

Figura l - (a) Construção de bissetriz com o compasso; (b) com o GeoGebra.

Dispositivos distintos contribuem, diferentemente, em nosso aprendizado. Interagindo com eles, seguimos procedimentos ou conceitos já constituídos ou geramos outros. Na verdade, o grande desafio é produzir novos conceitos matemáticos. Sim, é possível! Por exemplo, as operações com medida de ângulos usando graus, minutos e segundos não devem mais fazer parte do currículo escolar. Um ambiente de geometria dinâmica (AGD), o GeoGebra, por exemplo, nos fornece essas medidas e não usa somente valores inteiros para ângulos. Portanto, a realização de operações não precisa mais constar no planejamento, mas a medição e a comparação, certamente, serão reconfiguradas. Ao invés de calcular, o que podemos fazer será interpretar e analisar medidas variadas. Além do mais, construir apenas uma bissetriz com o GeoGebra, conforme ilustrado na Figura 1b, ${ }^{9}$ é explorar muito pouco desse recurso, que permite ao usuário realizar e analisar diferentes construções, conceitos, propriedades e estabelecer relações.

O compasso, embora possa ser constantemente aberto e fechado, é um dispositivo sem mobilidade. Um AGD usado em um desktop, apesar de cons- 
truções com movimentos variados, também não a possui. Todavia, um AGD usado em um smartphone dispõe da mobilidade. Nos dois primeiros casos, o sujeito precisa se dirigir até cada um dos aparatos e, ao pegá-los, provoca a sua mobilidade. No segundo, o dispositivo está, em potência, provido da mobilidade, embora ele possa ficar momentânea e provisoriamente imóvel. Cabe, então, acrescentar nessa reflexão a ideia de (i)mobilidade.

De acordo com Lemos (2009), a mobilidade pode ser vista em seu aspecto físico ou virtual (informacional). Essa navegação, essa ruptura temporária da dimensão física da mobilidade mexe, inclusive, na nossa percepção. Chegamos a um auditório para ouvir uma palestra, sentamos, conversamos com quem está ao nosso lado. Estamos "cada um no seu quadrado!". ${ }^{10}$ Estamos em uma região fronteiriça, que nos permite isolar ou viajar em conversas com pessoas ou assuntos inesperados.

Pensar a (des)territorialização é pensar na ruptura de fronteiras. A gente vive ao mesmo tempo que navega pelos mundos. Sentimo-nos livres, mas também temos a sensação de estar aprisionados. Conforme Augé (2010), a questão espacial, de territorialidade, é paradoxal. Somos livres com a internet, mas também estamos sendo regulados. Esse paradoxo não é só do nosso tempo presente, ele é da contemporaneidade - evidentemente, com contornos diferentes em cada época. Como diz Augé (2010), é preciso repensar a fronteira, essa realidade constantemente renegada e reafirmada insistentemente sob formas enrijecidas, que funcionam como interditos e provocam exclusões.

Refletir sobre fronteira, quando você tem próximos distantes, distantes próximos, é tentar compreender essas contradições que afetam a história contemporânea, pois as fronteiras não se desfazem, elas se redesenham (Augé, 2010). Nesse sentido, a mobilidade vai, no tempo presente, ser enriquecida com a ubiquidade (Couto; Porto; Santos, 2016). Todos queremos uma potente mobilidade, física ou virtual. Mas seria ela a mesma sem a ubiquidade, ou seja, a possibilidade de estarmos onipresentes? Para isso, precisamos olhar as transformações da informática.

\section{Dimensão sociotécnica: ubiquidade, convergência, conectividade}

$\mathrm{O}$ avanço computacional tem mudado a forma de ser e estar no mundo da vida e, consequentemente, de aprender, de ensinar e de pesquisar. A sociotécnica surge com a técnica. Graças a ela a conectividade nos permite navegar por lugares não imaginados. Da mesma forma que ela nos permite voar, ela também nos aprisiona. Permite-nos participar de coletivos variados, mas nos isola em um mundo de suposta felicidade e prazer constantes. A partir de Augé (2010), cabe destacar que o distanciamento e a aproximação entre pessoas, objetos ou lugares; o empoderamento e o enfraquecimento de relações interpessoais; as possibilidades variadas de obtenção de informação; e a pouca análise criteriosa que se faz dela são, dentre outros, paradoxos que os dispositivos móveis trazem para o nosso tempo. 
Lévy (1996) vem também lembrar que estradas e carros, correntes e navios, velas e ventos reúnem ou separam as culturas, influem nas formas e nas densidades das redes. Portanto, a inteligência e a cognição são o resultado de redes complexas onde interage um grande número de atores humanos, biológicos e técnicos (Lévy, 1993). O autor cunha o termo "ecologia cognitiva", que é o estudo das dimensões técnicas e coletivas da cognição (ibidem). Portanto, com a sua mobilidade virtual (Lemos, 2009), os DMcTT podem ampliar nossas possibilidades de deslocamentos, de conexões e de ressignificações individuais ou coletivas.

Atualmente, estar conectado pressupõe a possibilidade de navegar por lugares (des)conhecidos. Temos dificuldade de imaginar nosso celular sem conexão à internet. Parece que falta (e falta mesmo!) algo em nossa corrente sanguínea. Do mesmo modo que a noção de dispositivo ou de mobilidade atravessa nossa história, também temos a conectividade. As formas de conectividade do nosso tempo são redimensionadas, e podemos transitar em espaços variados, observar comportamentos de outras culturas e, até mesmo, conversar com (des) conhecidos. O que pensar de nossas formas de navegar e comunicar, a partir das Figuras 2?
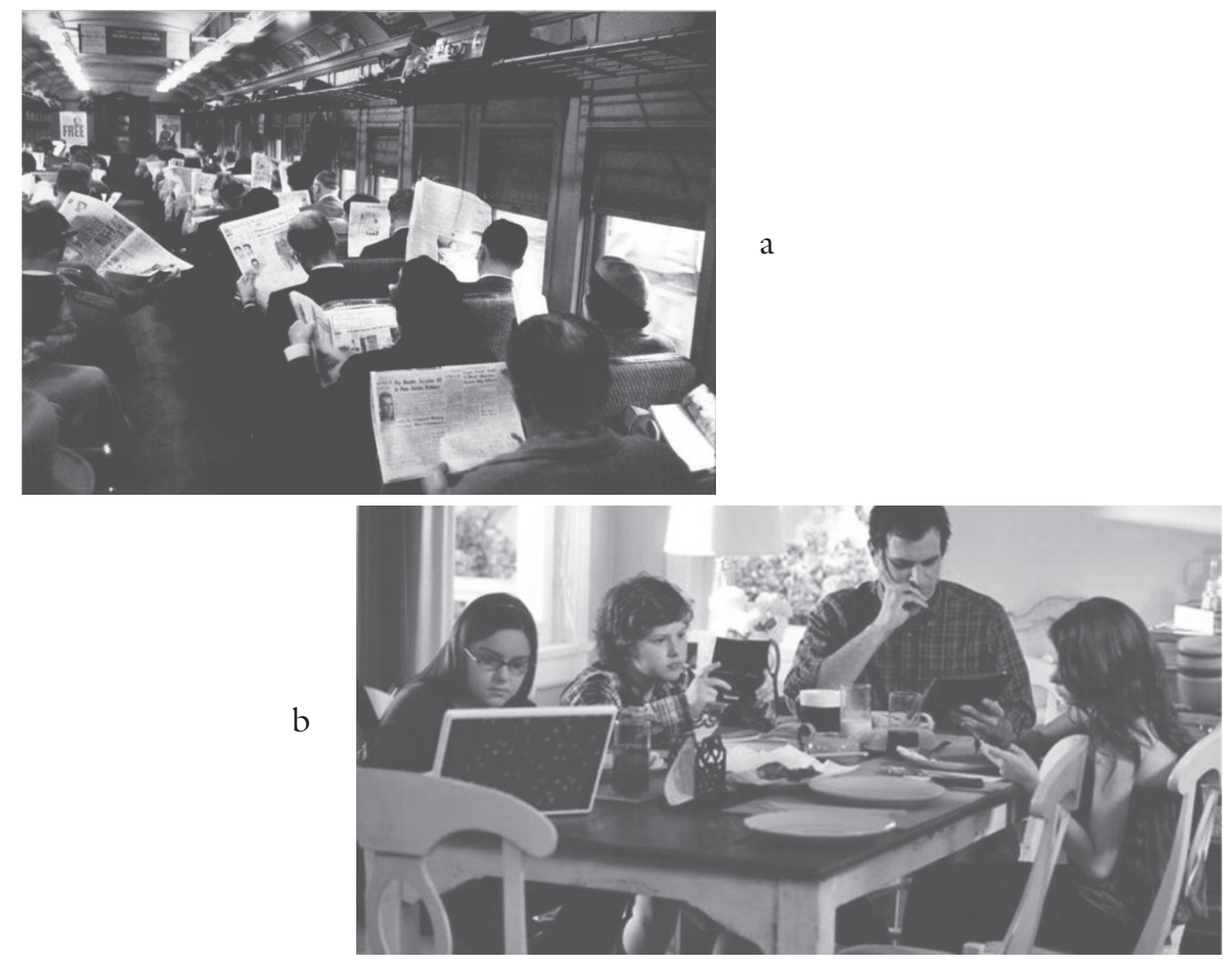

Fonte: Google pictures. ${ }^{11}$

Figura 2 - (a) Leitura em trem; (b) em família reunida. 
Elas mexem conosco, nos transportam, nos inquietam, nos amedrontam. Você, leitor(a), já se viu em situação semelhante? Ambas as imagens o intrigam ou apenas a segunda? Atualmente às vezes assumimos uma postura saudosista, dizendo que sentamos à mesa e não conversamos. Interagimos por meio do nosso celular! Guardadas as devidas particularidades de cada tempo, seriam essas inquietações apenas do tempo presente? Será que, quando surgiram os aparelhos de televisão, houve mudança na comunicação entre as pessoas? Portanto, ao sermos sujeitos contemporâneos, não podemos manter fixo nosso olhar em apenas uma realidade (Agamben, 2009), nem, tampouco, considerar a tecnologia como solução dos nossos problemas, particularmente, os educacionais.

A convergência e a ubiquidade surgem graças ao avanço da informática. ${ }^{12}$ Impregnados dessas duas técnicas, o indivíduo e o coletivo se movimentam dialeticamente. Um aplicativo, que geralmente tem uma idealização para uso individualizado, é continuamente remodelado a partir do uso feito pelo seu dono. Portanto, a interação que auxiliará essa reconfiguração não é só a do humano com a máquina, mas a do humano com outros humanos, não necessariamente no próprio dispositivo, mas nos diferentes espaços transitados pelos indivíduos. Enfim, nossa subjetividade transita entre o individual e o coletivo, e a fronteira entre eles é tênue.

Nosso smartphone possui uma série de funcionalidades. Tiramos uma foto e podemos editá-la, compartilhá-la e usá-la na produção de conteúdos diversos. $\mathrm{Na}$ verdade, quase não usamos nosso telefone para realizar uma chamada. A convergência e a ubiquidade reconfiguraram a utilidade inicial do celular. Além do mais, com os DMcTT passamos da lógica do download (de sentar em frente ao computador, ligá-lo, conectá-lo via cabo, buscar e baixar o conteúdo) para upload, em que o conteúdo chega diretamente até nós mediante convites (SMS, timeline etc.) em diferentes formatos. Mudamos de uma lógica comunicativa centralizada e direcionada (um para todos) para uma dinâmica na qual o dispositivo funciona a partir dos usos do seu dono. Além de o dispositivo se configurar a partir das demandas do usuário, o sujeito passa a ter um papel importante na produção de conteúdos variados.

Os DMcTT também são formas de memória, nossa memória expandida. É uma modificação técnica que implica novas analogias e classificações de outros mundos práticos, sociais e cognitivos (Lévy, 1993). Em um AGD eu exploro, interajo, aprendo, individual e coletivamente, ${ }^{13}$ física ou virtualmente. ${ }^{14} \mathrm{O}$ dispositivo mexe comigo, e eu mexo com ele. Todavia, o que dizer dos meus sentimentos, ao aprender com essas interfaces?

\section{Dimensão perceptivo-afetiva: afeto, percepção}

A dimensão perceptivo-afetiva tem o afeto, os sentimentos e a sedução como algumas de suas características detonadoras. O afeto no sentido de ser afetado, de afetar-se (Skliar, 2014), de sentimentos emocionais, de percepções (Damásio, 2011). 
A forma com a qual nos apropriamos de tecnologias está em constante interação com o ambiente, ou seja, a tecnologia influencia o meio, e esse também reage com (ou sobre) ela (Maturana; Varela, 2001). Sendo, portanto, o smartphone uma tecnologia expansiva e não reparadora (Bolite Frant; Castro, 2009) do aspecto físico do nosso corpo, passamos a constituir com ele atividades que não faríamos sem o dispositivo.

O toque, como tecnologia, não é recente, mas a nossa percepção ao tocar a tela de um caixa eletrônico ou a de um ultrabook é a mesma de quando tocamos nossos celulares ou tablets? De modo similar, nossa percepção sensorial é diferente quando clicamos em mouse ou manuseamos um DMcTT? Usar mouse com fio não é a mesma coisa que utilizar a versão sem fio. Cada forma de manuseio promove em nosso cérebro mapeamentos diferentes. Esses podem ser de sensibilidade, de espacialidade ou de continuidade de manuseio direto no objeto ou a partir dele (Bairral, 2017).

Nessa dimensão, portanto, a singularidade - da mobilidade com o toque - deve ser levada em consideração, até porque nosso cérebro vai se ajustando ao que lhe é oferecido (Damásio, 2010), e interfaces com toques em tela estão trazendo novas configurações ao cérebro. Portanto, nosso corpo deve ser visto como a mente que compreende o nosso pensar, o nosso sentir e o nosso agir (Damásio, 2004). Cabe, portanto, destacar a distinção entre sentimento e emoção.

As emoções constituem ações acompanhadas por ideias e certos modos de pensar; os sentimentos emocionais são principalmente percepções daquilo que nosso corpo faz durante esse mesmo lapso de tempo (Damásio, 2011). Emoções são programas de ações ${ }^{15}$ complexos e em grande medida automatizados, engendrados pela evolução. As ações são complementadas por um programa cognitivo que inclui certas ideias e modos de cognição, mas o mundo das emoções é, sobretudo, feito de ações executadas no nosso corpo, desde expressões faciais e posturas até mudanças nas vísceras e no meio interno (Damásio, 2011). Por outro lado, sublinha Damásio, os sentimentos emocionais são as percepções compostas daquilo que ocorre em nosso corpo e na nossa mente quando uma emoção está em curso. No que diz respeito ao corpo, os sentimentos são imagens de ações, e não ações propriamente ditas; o mundo dos sentimentos é feito de percepções executadas em mapas cerebrais (Damásio, 2011). Uma emoção negativa, como o fracasso ao aprender matemática, leva à evocação de pensamentos sobre fatos negativos. O fogo emocional é a energia com a qual se perseguem, constantemente, as ideias a serem alcançadas (Mora, 2017). Enfim, nossa alegria ou tristeza altera o estado de nossos impulsos e motivações, mudando imediatamente nossa mistura de apetites e desejos (Damásio, 2011).

\section{Dimensão neurocognitiva: ambiente, linguagens, imagens}

Nosso organismo é constituído pela parceria cérebro-corpo. Ele interage com o ambiente como um conjunto, e não é a interação só do corpo ou só do cérebro (Damásio, 1996). Se o corpo e o cérebro interagem intensamente entre 
si, o organismo que eles formam interage de forma não menos intensa com o ambiente que o rodeia, e suas relações são mediadas pelo movimento do organismo e pelos aparelhos sensoriais.

As mudanças anatômicas em nosso cérebro ocorrem ao longo de nossa vida e com elas as capacidades, as habilidades e a própria personalidade que um indivíduo forja e desenvolve (Mora, 2017). Nossa mente, nosso corpo e o ambiente físico trabalham em constante sinergia (Moore-Russo; Viglietti, 2014). O espaço físico (a sala de aula, por exemplo) inclui diferentes aparatos (tecnológicos, cognitivos, culturais etc.) com os quais lidamos. ${ }^{16} \mathrm{~A}$ entrada deles em nossa vida (e corpo) altera nosso jeito de ser e estar no mundo (Idhe, 2002). Nosso ambiente também se reconfigura.

Por exemplo, dotadas de telefone fixo, as residências tinham uma configuração, um design. Geralmente, havia um espaço para o aparelho, um bloco para anotações, agenda de contatos etc. Às vezes, existia uma cadeira para sentarmos e falarmos. Sim, o telefone era para falar, apesar de as chamadas serem custosas! Com a possibilidade do telefone sem fio, essa disposição física passou a ser reconfigurada, e o atendente podia mover-se ao longo de um telefonema. O local para atendimento de chamadas não era mais tão fisicamente delimitado.

Com o surgimento da secretária eletrônica, nem a presença física de quem receberia a chamada era necessária. Com a chegada do celular e todas as suas reconfigurações (toques, aplicativos, redes sociais integradas etc.), o que tivemos? Uma das reconfigurações é a ampliação de nossos deslocamentos físicos e informacionais (Lemos, 2009). Deixarei um pouco nossas casas e descolamentos nela para olhar o nosso corpo e como ele tem sido objeto de análise em algumas investigações.

Na pesquisa no âmbito da cognição corporificada em educação matemática, a relação corpo-todo foi priorizada, dadas as particularidades dos dispositivos disponíveis à época (sensores acoplados em calculadoras gráficas) e pela própria natureza do estudo (Borba; Scheffer, 2004). Atualmente, com o surgimento de novas interfaces, podemos também analisar partes do nosso corpo mediante capturas de olhares projetados na tela (Hannula, 2018) ou mapeando toques feitos nela (Assis; Henrique; Bairral, 2018).

As manipulações em tela, foco das pesquisas desenvolvidas em nosso grupo, ${ }^{17}$ constituem uma nova forma de manifestação da linguagem e passam a fazer parte da nossa cognição corporificada (Bairral, 2017). Embora a possibilidade de tocar em tela não seja recente, a mobilidade e o tipo de sensibilidade e performance oferecidos por certos dispositivos o são e têm mexido conosco. Essas mudanças, que fazem parte de um processo criativo, geram inovação (Mora, 2017).

Alguns toques que fazemos em tela podem ser associados a gestos (fazer um zoom por exemplo), outros não se reduzem a eles e abrem uma nova agenda de investigação sobre formas de manipular com a tela, a partir dela ou direta- 
mente nela. Todas essas formas constituem manifestação e simulação de algum processo de pensamento. Embora estejam no âmbito imagético da linguagem, elas não se restringem apenas a gestos ou a expressões cinestésicas. Toques em tela engendram uma rede de movimentos variados, muitas vezes combinados e, assim, formam um sistema simbólico multifacetado (Bairral, 2017).

Sendo o cérebro a audiência cativa do nosso corpo, há um fluxo imagético (visual, auditivo, olfativo, gustativo, somato-sensitivo) construído quando mobilizamos objetos de fora do cérebro em direção ao seu interior, e quando reconstruímos objetos a partir da memória, de dentro para fora. Esse fluxo pictórico, composto também por palavras e por símbolos abstratos não imagéticos, pode ser denominado pensamento (Damásio, 2005). No caso do pensamento matemático, há que considerar que a conjunção gesto+fala+construção_na_ tela+toques+registro_pictórico+movimento_com_o_dispositivo+movimento_com_o_ corpo compõe, de igual relevância, o espectro cognitivo-linguístico do sujeito. Embora manifestações imagéticas, muitas vezes, sejam difíceis de serem capturadas ou analisadas sincronamente, não podemos valorizar apenas os registros escritos.

Mediante esse fluxo imagético, nosso cérebro constrói mapeamentos diversos, e a interação passa a ser uma ação cada vez mais primordial em nosso aprendizado. Skliar (2014) nos instiga, ao lembrar que nossa função como educadores é conversar com desconhecidos. O autor sublinha que toda conversa é uma tensão permanente entre diferentes formas de pensar e de pensar-se, de escutar e de escutar-se: existem dissonâncias, desentendimentos e incompreensões. Seriam essas situações desafiantes apenas do nosso tempo? Ou seriam tensões que se acentuam, talvez, pela velocidade com que a informática tem se modificado e nos alterado? Então, ao sermos afetados e, dada a necessidade de conversarmos de formas variadas com os desconhecidos, é importante considerarmos a dimensão discursivo-comunicativa.

\section{Dimensão discursivo-comunicativa: contexto, deslocamentos}

Discurso é uma prática comunicativa contextualmente situada. Estamos aqui, neste artigo, em um contexto discursivo. Em um espaço que tem regras explícitas e implícitas. Embora ocorra um ato comunicativo, não necessariamente temos interação entre mim (o autor) e você, o leitor(a). Toda interação é um ato comunicativo, mas nem toda comunicação detona um processo interativo. Interagir (sujeito-sujeito, sujeito-dispositivo) é uma ação imprescindível no desenvolvimento humano.

Um discurso se produz e se interpreta em contextos específicos. Embora articulado à cultura na qual está sendo (re)produzido, não é um ato comunicativo neutro. As fotos seguintes teriam um impacto diferente, se apresentassem apenas a Figura 3(a) e eu perguntasse o que você observava. Quando o faço, respostas frequentes são: números, data de calendário, mês de abril. Após essa conversa, ao mostrar a segunda, tirada por mim em Salvador, há sorrisos e expres- 
sões de surpresa. Mesmo quando apresentadas na Bahia, contexto supostamente familiar à produção desse anúncio (discurso imobiliário), as manifestações dos sujeitos foram similares.

a

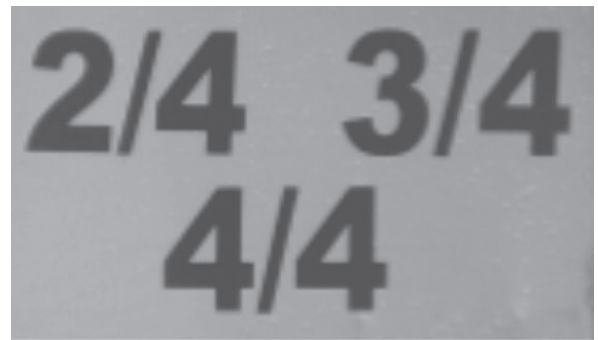

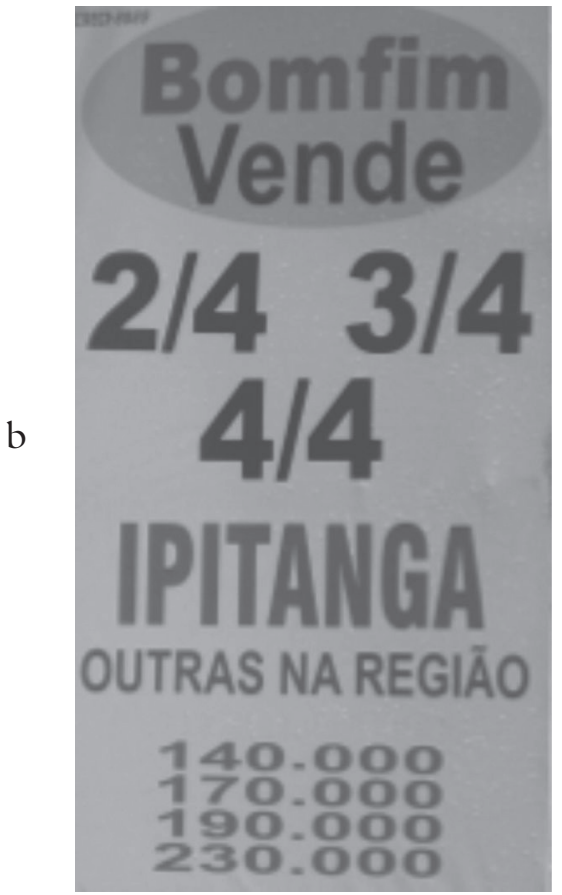

Fonte: Fotos do autor.

Figura 3 - (a) Só os números; (b) frações em contexto imobiliário.

A ideia da comunicação como deslocamento (Lemos, 2009) pode nos permitir um transporte, ainda que instantâneo ou pontual, ao contexto de produção da mensagem, de modo que possamos atribuir algum significado (estranhamento, conformidade etc.) a ela. Por ser um sistema de representação, ${ }^{18} \mathrm{O}$ discurso também reconfigura nossa experiência, nosso modo de pensar. Nesse processo consumimos, agregamos, produzimos e distribuímos conteúdos em diversos formatos, espaços e tempos.

Aproximando-nos(me) da última dimensão, trago aqui também Carlos Skliar (2014), ao enfatizar que deveríamos prestar mais atenção escrupulosa às máscaras institucionais com as quais pretendemos regular, administrar e, muitas vezes, destruir a conversa educativa. Com esse espírito estamos compondo a ação estratégica da nossa profissão, a que possui cunho político-pedagógico.

\section{Dimensão político-pedagógica}

Pensar nas dimensões anteriores e refletir sobre nosso papel como educadores é primordial. No mundo globalizado, um currículo deve contemplar aspectos culturais (de escolas, de regiões) e pessoais (de professores, de alunos), e valorizar características culturais locais, que não podem ser vistas como menores no processo educativo. Além do mais, não faz sentido pensar em universalização curricular. 
Da mesma forma que um aluno de uma escola da cidade de São Paulo pode conhecer o que acontece (história, arquitetura, linguagem, modo de vida, economia, meios de transporte, formas de divulgar a venda de imóveis, como revela a Figura $3 \mathrm{~b}$ etc.), em uma cidade do interior desse estado, o inverso também é importante. O desafio curricular é dar conta desse intercâmbio cultural, discursivo e cognitivo e da interação entre os aprendizes. Para isso, as tecnologias móveis podem ser muito úteis.

Por que fazemos pesquisa? Por que ensinamos? Por que nos tornamos professores? Por que formamos educadores? Está em nossas mãos, como formadores, como pesquisadores, continuar clamando por mudanças qualitativas no processo educativo, porque há muita coisa na contramão, na destruição de conquistas e de garantias, como, por exemplo, a recente Base Nacional Comum Curricular (BNCC) ou a "nova" Reforma do Ensino Médio. Currículo não é uma ação homogeneizadora, comum ou, muito menos, um conjunto - mínimo - de competências, previamente determinadas por agentes externos às instituições educativas.

Vivemos continuamente inovando, e ninguém duvida que as tecnologias digitais móveis podem contribuir com mudanças qualitativas nas intervenções docentes, no currículo e no aprendizado. Currículo é um uma estratégia educativa, portanto, política. A escola e os professores produzem política curricular em sua prática (Ball; Maguire; Braun, 2016).

Currículo é dinâmico e retroalimentado por (trans)formações e (re)significações efetivamente construídas pelo modo como os implicados produzem significados para a sua leitura do documento prescrito. A sala de aula de matemática deve favorecer uma comunicação pautada por interações, negociações e (re) construções de significados. Portanto, a garantia de êxito de um desenvolvimento curricular não está em determinações legais, embora essas sejam importantes. Porém elas não são determinantes para um sucesso prescrito e objetivamente mapeado (Bairral; Assis, 2018).

Para indicar um exemplo, com o compartilhador de aplicativos via Bluetooth, o MyAppSharer, já não precisamos de conexão para usar um AGD. Portanto, essa restrição da conectividade está superada, e podemos gerar novas formas de produzir e de desenvolver novas matemáticas com esses dispositivos. Uma das estratégias pedagógicas são as multitarefas, as possibilidades e os desdobramentos de uma situação na qual o aluno, individualmente ou em grupo, pode desenvolver, a partir dos seus próprios interesses, as próprias tarefas e outros temas de estudo. Sendo assim, temos que continuar investigando e criando ambiências para desenvolver formas de deixar pais, discentes e docentes conscientes sobre a importância do uso pedagógico de DMcTT.

\section{Deixando a tela em descanso}

Whether it is an eye that sees the reality of thing or whether it is an eye that see a world of fantasy. It is the quality of your eyes and the streng- 
Neste artigo propus seis dimensões que podem ser pensadas em práticas de ensino ou pesquisa com DMcTT. As dimensões, não hierárquicas ou ordenadas, possuem especificidades, mas elementos comuns. Por exemplo, eu poderia situar a conectividade em cada uma das seis dimensões, mas optei por construir uma linha argumentativa a partir de aspectos que podem ser diferenciais para a sustentação de cada uma das dimensões elencadas. Ou, ainda, a conectividade poderia ser pensada como uma dimensão. Portanto, dimensões, com a organização reflexiva que tracei, não são categorias. Embora disformes, elas são igualmente relevantes e trazem implicações diferenciadas ao desenvolvimento humano.

Além do mais, todas as outras dimensões poderiam estar incluídas na dimensão da contemporaneidade, pois é nesta que o sujeito está convidado a refletir sobre as diversas obscuridades do seu tempo (Agamben, 2009), que o faz sentir medo, insegurança, prazer etc. com os avanços tecnológicos. A reflexão sobre o que significa aprender deve estar na centralidade dos estudos voltados à escolarização.

Aprender, nos dias de hoje, não pode ser visto como o mesmo aprendizado de vinte anos atrás. É comum ouvirmos comparações entre aprendizados atuais e mais remotos, mas será que os sujeitos do tempo presente não estão aprendendo? Como pode uma pessoa jogar e ganhar brilhantemente em jogos eletrônicos e ser reprovado em matemática na escola? Soluções milagrosas como currículos universais ou resultados aferidos a partir de avaliação de larga escala tampouco são promissores de mudanças qualitativas em nossa Educação. $\mathrm{O}$ investimento na formação continuada de professores, na melhoria das condições de trabalho docente e na infraestrutura das escolas, de modo que os currículos possam valorizar processos criativos, de interação e de colaboração, oferece algumas das possibilidades de melhoria.

Enfim, ficam aqui alguns traços para que o leitor possa mover-se pelo seu próprio compasso e delimitar suas dimensões.

Notas

1 Texto elaborado a partir da palestra de abertura proferida pelo autor no III Fórum do GT6 (Educação Matemática, Tecnologias Informáticas e Educação a Distância) da Sociedade Brasileira de Educação Matemática, ocorrido nos dias 23 e 24.3.2018 no IFES, campus Vitória/ES.

2 "Lidar" está sendo usado em sentido amplo, ou seja, significa usar, ver, manusear, tocar, sentir etc.

3 Para evitar repetições excessivas e tornar a leitura mais agradável usarei como sinônimos de dispositivo as palavras aparato, interface, instrumento, máquina, mecanismo e recurso. 
4 Fruto de pesquisa financiada pelo CNPq.

5 A partir do dicionário (<https://www.dicio.com.br/dimensao/>) o termo dimensão está sendo usado em sentido figurado, isto é, como âmbito significativo de alguma coisa (real ou abstrata). Neste texto não há nenhuma correlação com significados oriundos da ciências exatas tais como (espessura, extensão, coordenadas etc.). Acesso em: 8 jul. 2018.

6 Agradeço aos pós-graduandos Alexandre Assis, Arlen Lacerda, Felipe Marques, George Bravo, Rhomulo Menezes, Thaís Settimy e Wagner Marques, e demais integrantes do Gepeticem a inspiração e colaboração nesta produção.

7 Os estudos do transnacionalismo de Alejandro Portes trazem interessantes reflexões sobre mobilidade, território e fronteira, particularmente, voltadas ao contexto da imigração. O que seria, por exemplo, pensarmos hoje na constituição de redes, quando um indivíduo dispõe da mobilidade virtual para o seu planejamento migratório?

8 Disponível em: <https://www.google.com/search?biw=1267\&bih=613\&tbm=isch \&sa=1\&ei=tNVBW_itA7SQmgX0y5GIDQ\&q=construcao+de+bissetriz+com+geog ebra\&oq $=$ construcao+de+bissetriz + com + geogebra\&gs_l=img.3 ..53759.55097.0.56 359.8.8.0.0.0.0.158.447.6j1.7.0...0...1c.1.64.img..1.0.0...0.zjNwJK5PpWU\#img $\mathrm{rc}=>$ Acesso em: 8 jul. 2018.

9 A figura ilustra o início da construção do ângulo.

10 Essa é uma expressão usual na cidade do Rio de Janeiro. Ela significa cada um na sua, que cada um tem a sua opinião, que não temos o direito de opinar sobre o que o outro faz, gosta etc.

11 Disponível em: <https://www.google.com/search?biw=1267\&bih=613\&tbm=isch \&sa=l\&ei=tNVBW_itA7SQmgX0y5GIDQ\&q=construcao+de+bissetriz+com+geog ebra\&oq $=$ construcao + de + bissetriz + com + geogebra\&gs_l=img.3...53759.55097.0.56 359.8.8.0.0.0.0.158.447.6j1.7.0...0...1c.1.64.img..1.0.0...0.zjNwJK5PpWU\#img $\mathrm{rc}=>$ Acesso em: 8 jul. 2018.

12 Pesquisas inovadoras na educação matemática, por exemplo, com realidade aumentada (Maurício Rosa, UFRGS), com sensores acoplados em calculadoras gráficas (Janete Bolite Frant, UFRJ; Nilce Scheffer, UFFS), com produção de vídeos por alunos ou professores (Marcelo Borba, UNESP-Rio Claro/SP), ou com o uso de rastreadores de olhares em tela (Markku Hannula, Univ. Helsinki, Finlândia), não seriam possíveis sem o avanço da informática.

13 Acesse: <http://www.gepeticem.ufrrj.br/portal/materiais-curriculares/pontos-notaveis-de-um-triangulo/> e veja, além de outros conteúdos em um AGD, outra forma de se conectar e aprender. Acesso em: 27 jul. 2018.

14 Visite online o Museu Universitário de História Natural e da Instrumentação Científica da Universidade de Modena e Reggio Emilia e descubra outras possibilidades de aprender mexendo em compassos. Disponível em: <http://archivioweb.unimore.it/ theatrum/macchine/_00lab.htm> Acesso em: 27 jul. 2018.

15 Itálicos no original.

16 "Lidar" está sendo usado em sentido amplo, ou seja, significa usar, ver, manusear, tocar, sentir etc.

17 Disponível em: <www.gepeticem.ufrrj.br>. 
18 Considere aqui as formas variadas de registro (pictórico, gráfico, numérico, tabular, algébrico etc.), sejam elas geradas de forma estática ou dinâmica e manifestadas isolada ou articuladamente.

19 Este artigo estava sendo produzido quando estive no parque das esculturas na cidade de Umea, na Suécia, em julho de 2018. Graças a mobilidades e desterritorializações, pude conhecer trabalhos dessa artista e perceber que essa sua ideia poderia estar presente fisicamente registrada neste texto, pois devemos deixar fluir a qualidade e a expressão de nosso olhar, sem impedimentos e com muita fantasia.

\section{Referências}

AGAMBEN, G. O que é o contemporâneo? e outros ensaios. Chapecó: Argos, 2009.

ASSIS, A.; HENRIQUE, M. P.; BAIRRAL, M. Captura e análise de interações em telas sensíveis ao toque. In: SEMINÁRIO INTERNACIONAL DE PESQUISA EM EDUCAÇÃO MATEMÁTICA, 7., (VII SIPEM). Foz do Iguaçu-PR, Brasil, 2018 (submetido).

AUGÉ, M. Por uma antropologia da mobilidade. Trad. Rachel Rocha de A. Barros e Bruno César Cavalcanti. Maceió: Edufal; Unesp, 2010.

BAIRRAL, M. A. As manipulações em tela compondo a dimensão corporificada da cognição matemática. Jornal Internacional de Estudos em Educação Matemática (JIEEM), v.10, n.2, p.104-11, 2017.

BAIRRAL, M. A.; ASSIS, A. R. de. Educação Matemática e currículo: processos para além da Educação Básica. In: SARTÓRIO, L. A. V.; LINO, L. A.; SOUZA, N. M. P. de. (Ed.) Politica educacional e dilemas do ensino em tempo de crise: juventude, currículo, reformas do ensino e formação de professores. São Paulo: Livraria da Física, 2018. p.187-208.

BALL, S. J.; MAGUIRE, M.; BRAUN, A. Como as escolas fazem as politicas: atuação em escolas secundárias. Ponta Grossa: Editora UEPG, 2016.

BOLITE FRANT, J.; CASTRO, M. R. Um modelo para analisar registros de professores em contextos interativos de aprendizagem. Acta Scientiae, v.11, n.1, p.31-49, 2009.

BORBA, M. C.; SCHEFFER, N. F. Coordination of multiple representations and body awareness. Educational Studies in Mathematics, n.57, p.1-20, 2004.

COUTO, E.; PORTO, C.; SANTOS, E. APP-Learning: experiência de pesquisa e formação. Salvador: EDUFBA, 2016.

DAMÁSIO, A. R. O erro de Descartes: emoção, razão e o cérebro humano. Trad. D. Vicente e G. Segurado. São Paulo: Cia. das Letras, 1996.

Em busca de Espinosa: prazer e dor na ciência dos sentimentos. São Paulo: Cia. das Letras, 2004.

- O mistério da consciência: do corpo e das emoções ao conhecimento de si.

Trad. L. T. Motta. 7. ed. São Paulo: Cia. das Letras, 2005.

E o cérebro criou o homem. São Paulo: Cia. das Letras, 2011.

HANNULA, M. From anxiety to engagement: History and future of research on mathematics-related affect. In: CONFERENCE OF THE INTERNATIONAL GROUP FOR THE PSYCHOLOGY OF MATHEMATICS EDUCATION, $42^{\text {th }}$. Umea, 2018. 
IHDE, D. Bodies in technology. Minneapolis - London: University of Minnesota Press, 2002 .

LEMOS, A. Cultura da mobilidade. Famecos, Porto Alegre, v.1, n.40, p.28-35, 2009.

LÉVY, P. As tecnologias da inteligência. Rio de Janeiro: Editora 34, 1993.

O que é o virtual? Rio de Janeiro: Editora 34, 1996.

MATURANA, H. R.; VARELA, F. J. A árvore do conhecimento: as bases biológicas da compreensão humana. Trad. H. Mariotti e L. Diskin. 9.ed. São Paulo: Palas Athena, 2001.

MOORE-RUSSO, D.; VIGLIETTI, J. M. Embodied cognition across dimensions of gestures. Considering teachers' responses to three-dimensional tasks. In: EDWARDS, L.; FERRARA, F.; MOORE-RUSSO, D. (Ed.) Emerging perspectives on gesture and embodiment in mathematics. New York: Information Age Publishing, 2014. p.137-227.

MORA, F. Cómo funciona el cerebro. 5.ed. Madrid: Alianz, 2017.

RIBEIRO, S. Tempo de cérebro. Estudos Avançados, São Paulo, v.27, n.77, p.7-22, 2013.

SKLIAR, C. Desobedecer a linguagem: educar. Belo Horizonte: Autêntica, 2014.

RESUMO - Dispositivos móveis com toques em tela - smartphone ou tablet - constituem uma extensão física do corpo, e a comunicação que tais interfaces promove passa a ser entendida como deslocamento. Considerando especificidades como mobilidade, convergência e ubiquidade, o artigo propõe seis dimensões (contemporaneidade, sociotécnica, neurocognitiva, perceptivo-afetiva, discursivo-comunicativa, político-pedagógica) que podem ser consideradas em processos de ensino, de aprendizagem ou de pesquisa no campo das Humanidades, particularmente na Educação. As dimensões são delimitadas com traços da contemporaneidade.

PALAVRAS-CHAVE: Cognição corporificada, Toques em tela, Smartphone, Tablet.

ABSTRACT - Mobile touchscreen devices - smartphones or tablets - constitute a physical extension of the body, and the communication that such interfaces enables is now understood as displacement. Considering specificities such as mobility, convergence and ubiquity, this article proposes six dimensions (contemporaneity, socio-technical, neuro-cognitive, perceptive-affective, discursive-communicative, political-pedagogical) that can be considered in teaching, learning or research in the Humanities, particularly in Education. Dimensions are delimited with traces of contemporaneity.

KEYWORDS: Embodied cognition, Touchscreen, Smartphone, Tablet.

Marcelo Almeida Bairral é professor associado da Universidade Federal Rural do Rio de Janeiro. É doutor em Educação Matemática pela Universidade de Barcelona e pósdoutor em Educação Matemática pela Universidade do Estado de Nova Jersey (Estados Unidos) e pela Universidade de Turin (Itália). @ - mbairral@ufrrj.br

Recebido em 6.8.2018 e aceito em 3.9.2018.

I Universidade Federal Rural do Rio de Janeiro, Rio de Janeiro, Rio de Janeiro, Brasil. 
